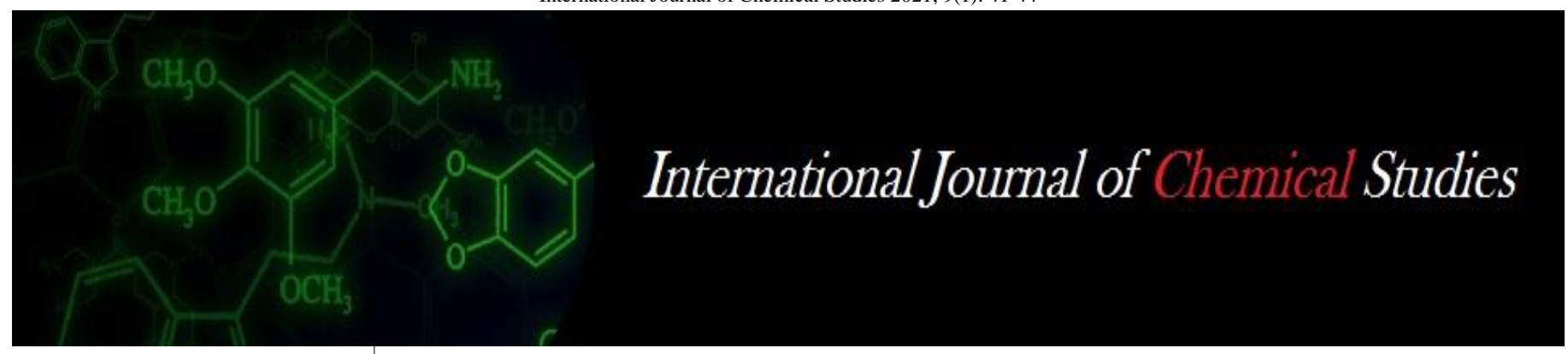

P-ISSN: 2349-8528

E-ISSN: 2321-4902

www.chemijournal.com

IJCS 2021; 9(1): 41-44

(C) 2021 IJCS

Received: 18-11-2020

Accepted: 23-12-2020

\section{Jalilur Rahman}

Department of Chemistry,

Shahjalal University of Science and Technology, Sylhet,

Bangladesh

\section{Md. Abdul Malek}

Department of Chemistry,

Shahjalal University of Science and Technology, Sylhet,

Bangladesh

Rehana Pervin

Department of Chemistry,

Shahjalal University of Science and Technology, Sylhet,

Bangladesh

\section{Shameem Ara Begum}

Department of Chemistry, Shahjalal University of Science and Technology, Sylhet, Bangladesh
Corresponding Author: M Jalilur Rahman

Department of Chemistry,

Shahjalal University of Science and Technology, Sylhet,

Bangladesh

\section{Electron-transfer oxidation of Organo-cuprates with Benzophenone: Synthesis of Biaryls}

\author{
M Jalilur Rahman, Md. Abdul Malek, Rehana Pervin and Shameem Ara \\ Begum
}

DOI: https://doi.org/10.22271/chemi.2021.v9.i1a.11596

\begin{abstract}
A mild and simple way to synthesize Biaryls from aryl bromides via formation of organo-cuprate complexes has been developed. The Organo-cuprates $\left\{\mathrm{Ar}_{2} \mathrm{CuMgBr} \cdot \mathrm{Mg}(\mathrm{I}) \mathrm{Br}\right\}$, generated from Arylmagnesium bromide and half equivalent of copper(I) iodide in dry THF at lower temperature under nitrogen, underwent electron-transfer oxidation with an aryl ketone benzophenone producing homocoupled Biaryls in moderate yields. Aryl bromides either with electron-donating or with electronwithdrawing substituents were smoothly transformed into the corresponding Biaryls through formation of aryl Grignard reagents and Organo-cuprate complexes in a one pot reaction under this electron-transfer oxidation procedure.
\end{abstract}

Keywords: Aryl bromides, Organo-cuprates, electrons-transfer oxidation, Biaryls

\section{Introduction}

Transition metal mediated aryl-aryl bond formation is one of the most powerful tools in modern organic synthesis ${ }^{[1-3]}$. Biaryl skeletons and their hetertoaromatic analogues are widely distributed in dyes, natural products, bioactive compounds, functional polymers and some ligands in catalysis etc ${ }^{[4-5]}$. For the synthesis of biaryls, the transition metals that are mostly used for either homo- or cross-coupling reactions, include copper, nickel, palladium and iron ${ }^{[6-10]}$. Metallic copper which was used in the original Ullmann reaction has been followed by a number of coupling reagents including activated metallic copper, copper(I) and copper(II) salts for the construction of biaryls ${ }^{[11-14]}$.

One of the favorable methods for the homo-coupling of the ligands $(\mathrm{R})$ on the copper atom in an organo-cuprate is its oxidative decomposition with suitable electron acceptor. The organocuprates can be formed from readily accessible organolithiums or Grignard reagents and half equivalent of copper (I) salts at lower temperatures. The oxidative coupling of organo-cuprates like Gilman cuprates $\left(\mathrm{R}_{2} \mathrm{CuLi}\right){ }^{[15]}$ or Lipshutz cuprates $\left\{\mathrm{R}_{2} \mathrm{Cu}(\mathrm{CN}) \mathrm{Li}_{2}\right\}^{[16]}$ with molecular oxygen yielded coupling products ${ }^{[17-19]}$. Quite interestingly the Lipshutz cuprate intermediates, derived from copper(I) cyanide and two equivalents of aryllithiums, have been found to undergo electron-transfer oxidation with 1,4-benzoquinones to give homo-coupled biaryls in good to excellent yields ${ }^{[20-21]}$. However this electron-transfer oxidation procedure has found its utility in the production of symmetric macrocyclic oligoarylenes like nonaphenylenes and dodecaphenylenes from 4,4"-dihalo-o-terphenyls, and pentadecaphyenylenes from $4,4^{\prime \prime \prime \prime}$ dihaloquinquephenyls ${ }^{[22-24]}$. Recently, we reported the formation of biaryls in moderate yields through electron-transfer oxidation of organo-cuprates with benzil (a 1,2-diketone) ${ }^{[25]}$.

In this paper, we report the construction of biaryls through electron-transfer oxidation of organo-cuprates with an aryl ketone benzophenone. The organo-cuprate complexes were prepared from aryl magnesium bromides and copper (I) iodide at lower temperature. Electrontransfer oxidation of these cuprate-complexes with benzophenone under inert condition yielded homo-coupled biaryls in moderate yields along with the formation of benzophenone ketyl radical. 


\section{Experimental}

\subsection{General}

The solvents used were dried and purified by the usual techniques: tetrahydrofuran (THF) was distilled from benzophenone ketyl under nitrogen atmosphere; $n$-hexane and dichloromethane were simply distilled without using any drying agent. The melting points of the synthesized compounds were determined with Yanaco MP-500D melting point apparatus. The NMR spectra were measured on a Bruker Biospin 400 spectrometer using tetramethylsilane (TMS) as an internal standard. The mass spectra were recorded on a Shimadzu GCMS-QP2010 spectrometer.

\subsection{General procedure for the synthesis of biaryls through electron-transfer oxidation of Organo-cuprates}

Activated Mg-turning (2 mmol) and a small magnetic stirrer bar were taken in a two neck round-bottomed flask. This is then equipped with a rubber septum at one end and a threeway stop-cock connected to a nitrogen balloon at the other end. In a similar fashion an aryl bromide $1(2 \mathrm{mmol})$ was taken into another two-necked round-bottomed flask. Using a syringe and a needle, dry THF ( $2 \mathrm{ml})$ was added to the flask containing the aryl bromide and then the resulting THF solution was transferred to the flask containing $\mathrm{Mg}$ turning under nitrogen atmosphere. Within few minutes exothermic reaction started. To complete the formation of the Grignard reagent, the reaction mixture was stirred at room temperature for 1 hour. A $10 \mathrm{~mL}$ portion of dry THF was then added to the prepared Grignard reagent in order to dilute it. The resulting diluted Grignard reagent was then cooled to $-5{ }^{\circ} \mathrm{C}$ when copper (I) iodide $(1 \mathrm{mmol})$ was added in one portion. The reaction mixture was then vigorously stirred at -5 to $0{ }^{\circ} \mathrm{C}$ under nitrogen for 40 minutes to compete the formation of the orgno-cuprate complex. The electron-acceptor benzophenone $(2.0 \mathrm{mmol})$ was added in one portion under nitrogen, and the chilling bath was then removed. The reaction mixture was then stirred at room temperature for another 3 hours to complete the reaction (TLC check up). To quench the reaction, water was added followed by the addition of dil. $\mathrm{HCl}$. The resulting mixture was then transferred into a separatory funnel where a $30 \mathrm{~mL}$ portion of dichloromethane was added. Two layers were separated and the organic layer was collected. The aqueous layer was again extracted with more dichloromethane. Anhydrous $\mathrm{MgSO}_{4}$ was added to the combined organic layer to remove any water. After the filtration, the solvent was removed in rotary vacuum evaporator to obtain the crude product. This was then chromatographed on a silica gel column eluting with $n$-hexane or $n$-hexane/dichloromethane mixed solvent system to get the pure biaryl 3.

\subsection{Biphenyl (3a)}

Colorless crystals (yield 36\%), mp 69.0-70.0 ${ }^{\circ} \mathrm{C}$ (lit ${ }^{[26]} \mathrm{mp}$ 69.0-69.5 $\left.{ }^{\circ} \mathrm{C}\right)$; EI MS: m/z $154\left(\mathrm{M}^{+}\right)$; ${ }^{1} \mathrm{H}$ NMR $\left(\mathrm{CDCl}_{3}, 400\right.$ $\mathrm{MHz}): \delta(\mathrm{ppm}) 7.62(\mathrm{~d}, J=8.4 \mathrm{~Hz}, 4 \mathrm{H}), 7.46(\mathrm{t}, J=7.8 \mathrm{~Hz}$, $4 \mathrm{H}), 7.37(\mathrm{t}, J=7.4 \mathrm{~Hz}, 2 \mathrm{H}) ;{ }^{13} \mathrm{C} \mathrm{NMR}\left(\mathrm{CDCl}_{3}, 100 \mathrm{MHz}\right): \delta$ (ppm) 141.2, 128.7, 127.2, 127.1.

\subsection{Dimethylbiphenyl (3b)}

Colorless crystals (yield 47\%); mp 119.0-120.0 ${ }^{\circ} \mathrm{C}$, (lit [26]. mp 119.5-120.0 $\left.{ }^{\circ} \mathrm{C}\right)$; EI-MS m/z $182\left(\mathrm{M}^{+}\right) ;{ }^{1} \mathrm{H}$ NMR $\left(\mathrm{CDCl}_{3}\right.$, $400 \mathrm{MHz}) \delta 7.49(\mathrm{~d}, J=8.0 \mathrm{~Hz}, 4 \mathrm{H}), 7.24(\mathrm{~d}, J=8.0 \mathrm{~Hz}, 4 \mathrm{H})$, $2.40(\mathrm{~s}, 6 \mathrm{H}) ;{ }^{13} \mathrm{C} \mathrm{NMR}\left(\mathrm{CDCl}_{3}, 100 \mathrm{MHz}\right) \delta 138.3,136.7$, $129.4,126.8,21.0$.

\subsection{Dimethylbiphenyl (3c)}

Colorless liquid (yield 38\%); EI-MS $\mathrm{m} / z, 182\left(\mathrm{M}^{+}\right)$; ${ }^{1} \mathrm{H}$ NMR $\left(\mathrm{CDCl}_{3}, 400 \mathrm{MHz}\right) \delta 7.43(\mathrm{~s}, 2 \mathrm{H}), 7.42(\mathrm{~d}, J=8.8 \mathrm{~Hz}, 2 \mathrm{H})$, $7.35(\mathrm{t}, J=7.6 \mathrm{~Hz}, 2 \mathrm{H}), 7.19(\mathrm{~d}, J=7.6 \mathrm{~Hz}, 2 \mathrm{H}), 2.46(\mathrm{~s}, 6 \mathrm{H})$; ${ }^{13} \mathrm{C} \mathrm{NMR}\left(\mathrm{CDCl}_{3}, 100 \mathrm{MHz}\right): \delta 141.3,138.2,128.6,127.9$, $127.8,124.2,21.5$.

\subsection{Dimethoxylbiphenyl (3d)}

Colorless crystals (yield 65\%); mp 176.0-177.0 ${ }^{\circ} \mathrm{C}$, (lit ${ }^{[27]}$. mp 176.5- $\left.177.0{ }^{\circ} \mathrm{C}\right)$; EI-MS $m / z 214\left(\mathrm{M}^{+}\right) ;{ }^{1} \mathrm{H} \mathrm{NMR}\left(\mathrm{CDCl}_{3}\right.$, $400 \mathrm{MHz}) \delta 7.48(\mathrm{~d}, J=8.8 \mathrm{~Hz}, 4 \mathrm{H}), 6.96(\mathrm{~d}, J=8.8 \mathrm{~Hz}, 4 \mathrm{H})$, $3.87(\mathrm{~s}, 6 \mathrm{H}) ;{ }^{13} \mathrm{C} \mathrm{NMR}\left(\mathrm{CDCl}_{3}, 100 \mathrm{MHz}\right) \delta 158.7,133.4$, $127.7,114.1,55.3$.

\subsection{Dibromobiphenyl (3e)}

Colorless crystals (yield 40\%), mp 165.0-166.0 ${ }^{\circ} \mathrm{C}$ (lit ${ }^{[27]}$. mp 166.5-167.0 $\left.{ }^{\circ} \mathrm{C}\right)$; EI MS: m/z 310/312/314 (1:2:1) $\left(\mathrm{M}^{+}\right) ;{ }^{1} \mathrm{H}$ NMR $\left(\mathrm{CDCl}_{3}, 400 \mathrm{MHz}\right): \delta(\mathrm{ppm}) 7.58(\mathrm{~d}, J=8.4 \mathrm{~Hz}, 4 \mathrm{H})$, $7.43(\mathrm{~d}, J=8.4 \mathrm{~Hz}, 4 \mathrm{H}) ;{ }^{13} \mathrm{C} \mathrm{NMR}\left(\mathrm{CDCl}_{3}, 100 \mathrm{MHz}\right): \delta$ (ppm) 138.9, 132, 128.5, 121.9.

\subsection{Dichlorobiphenyl (3f)}

Colorless crystals (yield 38\%), mp 147.0-148.0 ${ }^{\circ} \mathrm{C}$, (lit ${ }^{[27]}$. mp 148.0-149.0 $\left.{ }^{\circ} \mathrm{C}\right)$; EI-MS $m / z$ 222/224/226 (9:6:1) $\left(\mathrm{M}^{+}\right) ;{ }^{1} \mathrm{H}$ $\operatorname{NMR}\left(\mathrm{CDCl}_{3}, 400 \mathrm{MHz}\right) \delta 7.48(\mathrm{~d}, J=8.4 \mathrm{~Hz}, 4 \mathrm{H}), 7.42(\mathrm{~d}, J$ $=8.4 \mathrm{~Hz}, 4 \mathrm{H}) ;{ }^{13} \mathrm{C} \mathrm{NMR}\left(\mathrm{CDCl}_{3}, 100 \mathrm{MHz}\right) \delta 138.4,133.7$, $129.0,128.2$

\subsection{Difluorobiphenyl (3g)}

Colorless crystals (yield 38\%), mp 87.0-88.0 ${ }^{\circ} \mathrm{C}$, (lit ${ }^{[27]} \mathrm{mp}$ $\left.88.5^{\circ} \mathrm{C}\right)$; EI-MS $m / z, 190\left(\mathrm{M}^{+}\right) ;{ }^{1} \mathrm{H} \mathrm{NMR}\left(\mathrm{CDCl}_{3}, 400 \mathrm{MHz}\right) \delta$ $7.51(\mathrm{dd}, J=8.8$ and $5.2 \mathrm{~Hz}, 4 \mathrm{H}), 7.13(\mathrm{t}, J=8.8 \mathrm{~Hz}, 4 \mathrm{H}) ;{ }^{13} \mathrm{C}$ NMR $\left(\mathrm{CDCl}_{3}, 100 \mathrm{MHz}\right) \delta 163.4,161.4,136.4,136.3,128.6$, $128.5,115.7,115.6$.

\section{Results and Discussion}

As reported, the traditional Gilman cuprates $\left(\mathrm{R}_{2} \mathrm{CuLi} \cdot \mathrm{LiX}\right)$ or Lipshutz cuprates $\left(\mathrm{R}_{2} \mathrm{Cu}(\mathrm{CN}) \mathrm{Li}_{2}\right)$ undergo oxidative decomposition with molecular oxygen giving coupling products ${ }^{[17-19]}$ and also the Lipshutz cuprates of the type $\mathrm{Ar}_{2} \mathrm{Cu}(\mathrm{CN}) \mathrm{Li}_{2}$ under electron-transfer oxidation with 1,4benzoquinones give homo-coupled biaryls in excellent yields $[20,21]$. In our previous study we found that benzil, an aryl 1,2diketone, behaves as an electron acceptor in the electrontransfer oxidation of the organo-cuprate (derived from Grigard reagent and copper(I) iodide) leading to the formation of homo-coupled biaryls in moderate yields. ${ }^{25}$ In this study we have tried to carry out our electron-transfer oxidation procedure with an aryl ketone like benzophenone. We chose benzophenone as an electron acceptor, as its carbonyl function is flanked by two electron withdrawing aromatic rings, which help to stabilize its anion radical after its generation by electron acceptance. We know that benzophenone forms benzophenone ketyl radical during drying of diethyl ether or tetrahydrofuran (THF) with metallic sodium under inert atmosphere. As benzophenone accepts electron from metallic sodium forming stable benzophenone ketyl radical, we believe that this reagent can also accept electron from organo-cuprate giving the stable ketyl radical and diaryl copper (II) $\left(\mathrm{Ar}-\mathrm{Cu}^{\mathrm{II}}-\mathrm{Ar}\right)$ intermediate. This diaryl copper(II) may undergo reductive elimination to give the homo-coupling product biaryl. 
Table 1: Homo-coupling of aryl bromides via electron-transfer oxidation of Organo-cuprates

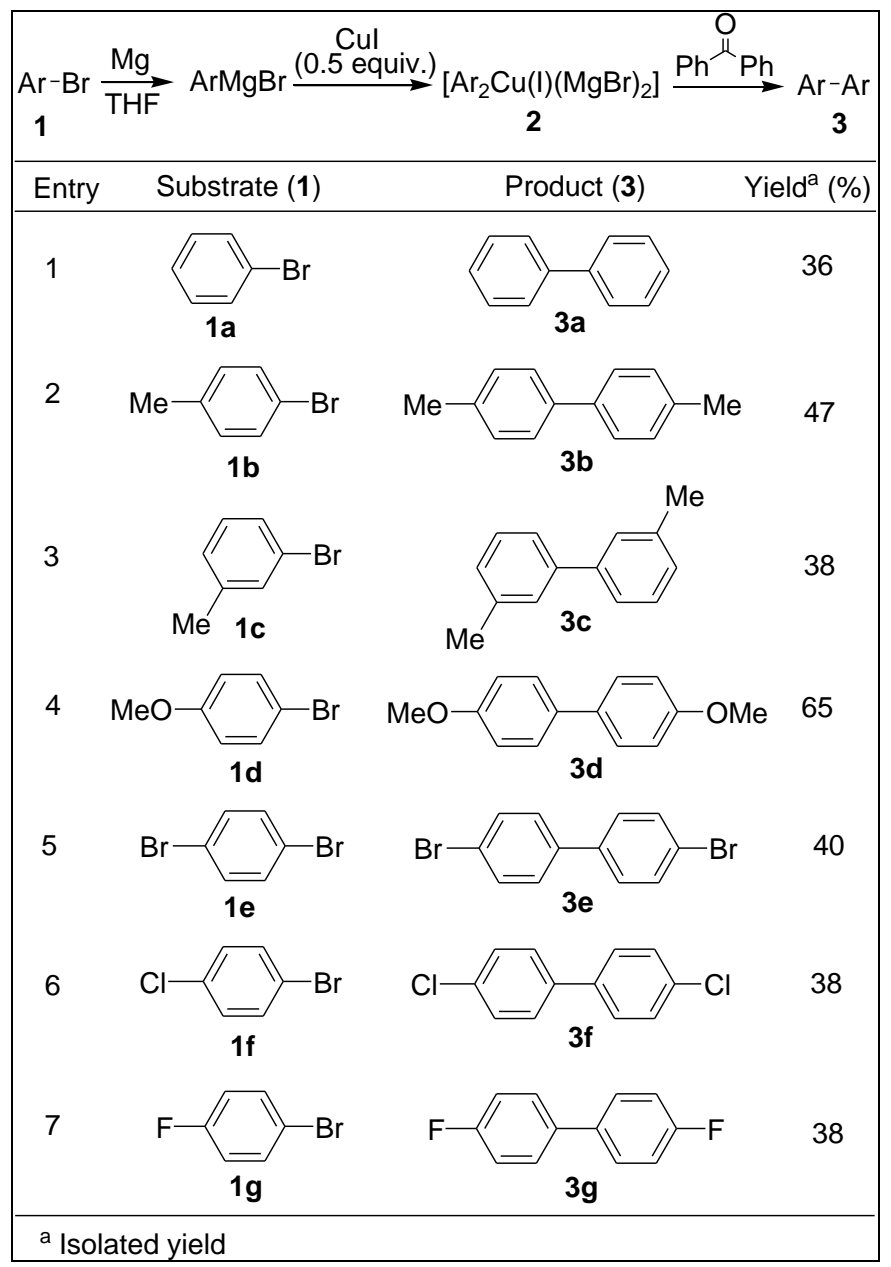

We prepared the aryl Grignard reagents from pure aryl bromides 1a-g and activated magnesium turnings in dry THF under nitrogen atmosphere. The Grignard reagents thus produced were then diluted with sufficient amount of dry THF before the formation of the cuprate complexes. Treatment of the diluted arylmagnesium bromide with half equivalent of copper(I) iodide at $-5{ }^{\circ} \mathrm{C}$ under an inert condition produced an organo-cuprate $\left[\left(\mathrm{Ar}_{2} \mathrm{Cu}(\mathrm{I})(\mathrm{MgBr})_{2}\right] 2\right.$ within one hour. When the electron-acceptor benzophenone was added to the cuprate-complex at lower temperature, the electron-transfer oxidation took place forming biaryl as homo-coupled product along with the formation of benzophenone ketyl radical (dark blue to violet coloration).

The electron-transfer oxidation procedure to synthesize biaryl was first investigated with the organo-cuprate complex generated from phenylmagnesium bromide and copper(I) salt. For the cuprate-complex to remain soluble in the solvent, sufficient amount of dry THF is necessary for the dilution of the prepared Grignard reagent before the addition of copper(I) salt. The temperature is lowered as well before addition of $\mathrm{CuI}$, because the Organo-cuprate formed may decompose even at lower temperature. When the oxidation of the cuprate complex was carried out with benzophenone, the homocoupling product biphenyl 3a was obtained in moderate yield (36\%) (Table 1, entry 1$)$.

We chose various aryl bromides 1a-g for our homo-coupling procedure via formation of the corresponding Organo-cuprate complexes. Aryl bromides either with electron-donating groups (e.g., 4-bromotoluene 1b, 3-bromotoluene 1c, and 4bromoanisole $1 \mathrm{~d}$ entry 2,3 , and 4 respectively) or with electron-withdrawing substituents (e.g., 1,4-dibromobenzene 1e, 1-bromo-4-chlorobenzene if and 1-bromo-4fluorobenzene $1 \mathrm{~g}$, entry 5, 6 and 7 respectively) smoothly transformed into the corresponding biaryls 3 in moderate yields under this electron-transfer oxidation procedure.

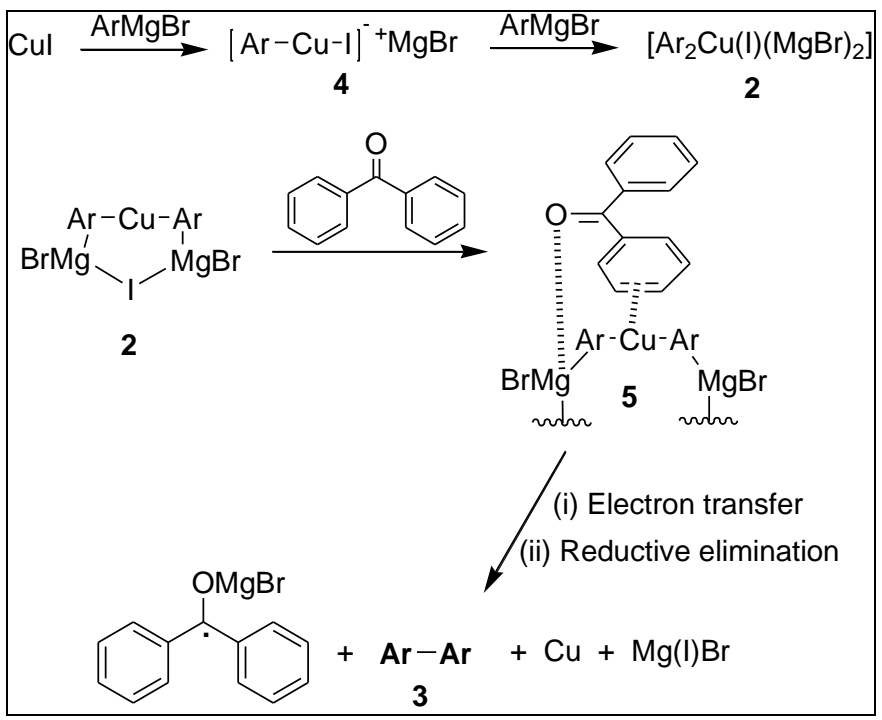

Scheme 1: Plausible Reaction Pathway

A plausible reaction pathway is depicted in the Scheme 1 . Copper (I) iodide first reacts with one equivalent of Arylmagnesium bromide to form a lower order cuprate 4 . This cuprate then combines with another equivalent of $\mathrm{ArMgBr}$ to give an Organo-cuprate complex 2 which on treatment with benzophenone (the electron-acceptor) forms a $\pi$-complex 5 . There might involve a magnesium-carbonyl and copper-arene coordinations in the $\pi$-complex 5 . The electrontransfer from the cuprate to the electron-acceptor (benzophenone), followed by reductive elimination yields the biaryls 3 as the homo-coupling products along with the formation benzophenone ketyl radical. During the work up, a disproportionation reaction of the ketyl radical might take place leading to the formation of benzophenone and diphenylmethanol. Thus a good amount of benzophenone has been recovered after each reaction.

\section{Conclusion}

In conclusion, a new methodology for the homo-coupling of aryl bromides through electron-transfer oxidation of the corresponding organo-cuprate with an aryl ketone has been developed. Benzophenone has been chosen as the aryl ketone, as its carbonyl function is flanked by two electronwithdarwing phenyl rings which help it to accept electron from the cuprate-complex and to stabilize the ketyl radical after its generation. The key step for the coupling of aryl groups on the copper atom is the electron-transfer from the organo cuprate-complex to the aryl ketone. Aryl bromides with either electron-donating or withdrawing substituents have smoothly been transformed into the corresponding biaryls under this electron-transfer oxidation procedure. It is noteworthy that a good amount of benzophenone is recovered after each reaction, which can be recycled.

\section{Acknowledgement}

This work has been supported in part by the Grant-in-aid for the scientific research from the University Research Center of Shahjalal University of Science and Technology (SUST), Sylhet, Bangladesh. We would like to thank Dr. Md. Mizanur 
Rahman, Professor, Department of Chemistry, SUST and Sub Project Manager (SPM, CP 3665) of Higher Education Quality Enhancement Project (HEQEP), Bangladesh for providing the aryl bromides for our research.

\section{References}

1. Alberico D, Scott ME, Lautens M. Aryl-aryl bond formation by transition-metal-catalyzed direct arylation. Chem. Rev 2007;107:174-238.

2. McGlacken GP, Bateman LM. Recent advances in arylaryl bond formation by direct arylation. Chem. Soc. Rev 2009;38:2447-2464.

3. Shi W, Liu C, Lei A. Transition-metal catalyzed oxidative cross-coupling reactions to form C-C bonds involving organometallic reagents as nucleophiles. Chem. Soc. Rev 2011;40:2761-2776.

4. Bringmann $\mathrm{G}$, Gulder T, Gulder TAM, Breuning $\mathrm{M}$. Atroposelective total synthesis of axially chiral biaryl natural products. Chem. Rev 2011;111:563-639.

5. Aldemir H, Richarz R, Gulder TAM. The biocatalytic repertoire of natural biaryl formation. Angew. Chem. Int. Ed 2014;53:8286-8293.

6. Do H-Q, Daugulis O. A general method for coppercatalyzed arene cross-dimerization. J Am. Chem. Soc 2011;133:13577-13586.

7. Gooßen LJ, Deng G, Levy LM. Synthesis of biaryls via catalytic decarboxylative coupling. Science 2006;313:662-664.

8. Gong X, Wu J, Meng Y, Zhang Y, Ye L-W et al. Ligandfree palladium catalyzed Ullmann biaryl synthesis: household reagents and mild reaction conditions. Green Chem 2019;21:995-999.

9. Yamaguchi J, Muto K, Itami K. Recent progress in nickel-catalyzed biaryl coupling. Eur. J Org. Chem 2013;2013:19-30.

10. Jana R, Pathak TP, Sigman MS. Advances in transition metal (Pd,Ni,Fe)-catalyzed cross-coupling reactions using alkyl-organometallics as reaction partners. Chem. Rev 2011;111:1417-1492.

11. Ullmann F, Bielecki J. Ueber synthesen in der biphenylreihe. Chem. Ber 1901;34:2174-2185.

12. Nishihara Y, Ikegashira K, Toriyama F, Mori A, Hiyama T. Homo-coupling reactions of alkenyl- and arylfluorosilanes mediated by a copper(I) salt. Bull. Chem. Soc. Jpn 2000;73:985-990.

13. Demir AS, Reis Ö, Emrullahoglu M. Role of copper species in the oxidative dimerization of arylboronic acids: synthesis of symmetrical biaryls. J Org. Chem 2003;68:10130-10134.

14. Jiang J, Du L, Ding Y. Aryl-aryl bond formation by Ullmann reaction: from mechanistic aspects to catalyst. Mini Rev Org Chem 2020;17:26-46.

15. Gilman H, Jones RG, Woods LA. The Preparation of Methylcopper and some observations on the decomposition of organocopper compounds. J Org. Chem 1952; 17:1630-1634.

16. Lipshutz BH, Wilhelm RS, Floyd DM. Chemistry of higher order, mixed organocuprates. 1 Substitution reactions at unactivated secondary centers. J Am. Chem. Soc 1981;103:7672-7674.

17. Whitesides GM, San Filippo J, Casey CP, Panek EJ. Oxidative-coupling using copper(I) ate complexes. J Am. Chem. Soc 1967;89:5302-5303.
18. Kauffmann T. Oxidative coupling via organo copper compounds. Angew. Chem. Int. Ed. Engl 1974;13:291305.

19. Lipshutz BH, Siegmann K, Garcia E. Kinetic higher order cyanocuprates: applications to biaryl synthesis. J Am. Chem. Soc 1991;113:8161-8162.

20. Miyake Y, Wu M, Rahman MJ, Iyoda M. Novel electrontransfer oxidation of Lipshutz cuprates with 1,4benzoquinones: an efficient homo-coupling reaction of aryl halides and its application to the construction of macrocyclic systems. Chem. Commun 2005, 411-413.

21. Miyake Y, Wu M, Rahman MJ, Kuwatani Y, Iyoda M. Efficient construction of biaryls and macrocyclic cyclophanes via electron-transfer oxidation of Lipshutz cuprates. J Org. Chem 2006;71:6110-6117.

22. Rahman MJ, Yamakawa J, Matsumoto A, Enozawa H, Nishinaga $\mathrm{T}$ et al. Synthesis of nonaphenylenes and dodecaphenylenes using electron-transfer oxidation of Lipshutz cuprates and formation of nanostructural materials from hexadodecyloxynonaphenylene. J Org. Chem 2008;73:5542-5548.

23. Rahman MJ, Shimizu H, Araki Y, Ikeda H, Iyoda M. Synthesis of pentadecaphenylenes, their inclusion properties and nanostructure formation with $\mathrm{C}_{60}$. Chem. Commun 2013;49:9251-9253.

24. Rahman MJ, Shimizu H, Hasegawa M, Iyoda M. Pentadecaphenylenes: synthesis, self-assembly and complexation with fullerene $\mathrm{C}_{60}$. Org. Chem. Front 2017;4:882-890.

25. Rahman MJ, Alahy M, Malek MA, Jannat S, Pervin R et al. Synthesis of biaryls through electron-transfer oxidation of organo-cuprates with benzyl. Int. J Chem. Stud 2017;5:162-165.

26. Pickett LW, Walter GF, France H. The ultraviolet absorption spectra of substituted biphenyls. J Am. Chem. Soc 1936;58:2296-2299.

27. Williamson B, Rodebush WH. Ultraviolet absorption spectra of organic molecules. II. The effect of substituent groups upon the absorption of biphenyl. J Am. Chem. Soc 1941;63:3018-3025. 